\title{
Analysis of the Thermal Characteristics and Thermal Management of Lithium-ion Power Battery
}

\author{
Jinfa Xie ${ }^{1, a}$, Ning $X_{i e}^{1,2, b}$, Yujie Liu', \\ ${ }^{1}$ Institute of Vehicle \& Traffic Engineering, Henan University of Science \& Technology, \\ Luoyang 471003, China; \\ ${ }^{2}$ Automotive Engineering Research Institute, China Automotive \\ Technology\&Research Center, Tianjin 300000, China \\ ajfxie@haust.edu.cn, bxieninga92@163.com, cyujielit@126.com \\ ${ }^{*}$ Ning Xie
}

\begin{abstract}
Keywords: Electric vehicle; NCM; Ambient temperatures; Battery thermal management.
\end{abstract}
\begin{abstract}
The heat generation mechanism of lithium-ion power battery was analyzed. It was concluded that the battery heating was related to the temperature coefficient of electro motive force, the SOC of the battery, the resistance of the battery, the current ratio . Based on the experiment, the important characteristic of the NCM were studied at different ambient temperatures. Experimental results are as follows. The discharge capacity increases with the increase of ambient temperature, and decreases with the increase of discharge ratio. The battery resistance rises obviously at low temperature, and discharge resistance is greater than the charging resistance. The SOC-OCV curve in the low temperature is lower than in the high temperature. The discharge efficiency curve gave the temperature reference range for normal operation of the battery. The study provides an important basis for the technology progress of battery thermal management technology for electric vehicles.
\end{abstract}

\section{Introduction}

The emission of traditional internal combustion engine vehicles causes environmental pollution and induces greenhouse effect and global warming, which makes the development of new energy vehicles be especially important. In recent years, electric cars obtain the unprecedented development and make great progress; however, questions also begin to come into sight. Power battery influences electric cars at the most [1]. The performance of power battery is closely related to environmental temperature, thermodynamic parameter of the battery, thermal management method and others $[2,4]$. Meanwhile, the capacity character, internal resistance value and open-circuit voltage curve of the battery are not only significant indicators that reflect the power battery performance, but also importance parameters that participate in the design of battery heat management system [5]. Therefore, to analyze the performance of the lithium ion battery under different environmental temperatures has a promote effect for the development of battery heat management system, which also has significant meaning to promote the development of efficient and clean new energy vehicles [6].

At present, researches on characteristics of lithium ion power battery mainly concentrate on theoretical research of the fever and heat dissipation model as well as experimental analysis of power battery characteristics under different environmental conditions. Both of them have not been combined to research the relation between significant indicators of lithium ion power battery characteristics and battery heating mechanism in depth. Take $3.67 \mathrm{~V} / 50 \mathrm{Ah}$ ternary lithium ion battery as the research object; analyze related factors influencing battery heating based on the heating mechanism of lithium ion battery and conduct experimental analysis on the important performance indicators of lithium ion power battery by cooperating with specific experiments. At the same time, to understand the battery performance more accurately, the analysis of discharging efficiency is added. 


\section{Heating Analysis of Lithium-ion Battery}

The heating problem of lithium-ion battery mainly includes two parts of battery heating and heat exchange with the environment [7].

\subsection{Heating mechanism analysis}

During actual analysis, the experimental analysis method proposed by Sato et al. is generally adopted. The method deems that battery heating mainly means the reversible heat $Q_{r}$ generated from the electrochemical reaction entropy change within the battery, Ohmic internal resistance heat $Q_{J}$ and polarization internal resistance heat $Q_{P}$ generated from battery. Except the above three heating sources, secondary reaction heat $Q_{s}$ will be generated during charge-discharge as well [8]. But $Q_{s}$ is relatively lower during the normal application of vehicles, and it can be neglected.

According to theories of chemical thermodynamics, under the equivalent press state:

$$
\Delta S=-\left(\frac{\partial \Delta G}{\partial T}\right)=n F\left(\frac{\partial E}{\partial T}\right) .
$$

Meanwhile, in consideration of external battery work, the electrical work made by $\Delta G$ includes:

$$
\begin{gathered}
W+Q_{\mathrm{r}}=\Delta H . \\
\Delta G=\Delta H-T \Delta S .
\end{gathered}
$$

Calculate from Formula (2) and (3):

$$
Q_{r}=T \Delta S=n F T\left(\frac{\partial E}{\partial T}\right) .
$$

In the above formula, $\Delta S$ is the entropy change; $\Delta H$ is the enthalpy change; $\Delta G$ is the gibbs free energy change; $(\partial E / \partial T)$ is the temperature coefficient of electromotive force; $T$ is the temperature $(\mathrm{K})$; $E$ is the battery electromotive force $(\mathrm{V})$, and $\mathrm{F}$ is the faraday constant.

The resistance will generate heat during the charge-discharge process of battery, which is heat of irreversible reaction; polarization internal resistance will produce polarization internal resistance heat during the charge-discharge process. The calculation formula of the heat generated is:

$$
\begin{aligned}
& Q_{J}=I^{2} R_{W} . \\
& Q_{P}=I^{2} R_{p} .
\end{aligned}
$$

In the formula, $Q_{J}$ is the Ohmic internal resistance heat $(\mathrm{J}) ; Q_{P}$ is the polarization internal resistance heat $(\mathrm{J}) ; I$ is the charge-discharge current(A); $R_{W} \mathrm{~s}$ the Ohmic internal resistance and $R_{p}$ is the polarization internal resistance $(\Omega)$.

Unite Formula (5) and (6), we can calculate the heat value $Q$ during the charge-discharge process of lithium-ion battery:

$$
Q=Q_{r}+Q_{J}+Q_{P}=n F T\left(\frac{\partial E}{\partial T}\right)+I^{2} R
$$

In the formula: $R$ is the total battery internal resistance $(\Omega)$.

\subsection{Heat exchange analysis}

The internal heat transfer method of lithium-ion battery can be divided into three methods of heat conduction, heat radiation and heat convection. We only need to consider heat conduction and heat convection during the normal application of vehicles

Heat conduction can be based on the fourier law:

$$
q_{1}=-k_{n} \frac{\partial t}{\partial n} .
$$

In the formula, $q_{1}$ is the heat flux $(\mathrm{W} / \mathrm{m} 2)$ during the heat conduction process; $k_{n}$ is the heat conductivity coefficient $(\mathrm{W} / \mathrm{m} * \mathrm{k}) ; \partial \mathrm{t} / \partial \mathrm{n}$ is the temperature gradient in $\mathrm{n}$ direction $(\mathrm{K} / \mathrm{m})$.

Heat convection can be expressed in the Newtonian cooling method:

$$
q_{2}=h_{f}\left(T_{s}-T_{b}\right) \text {. }
$$


In the formula: $q_{2}$ is the heat flux $\left(\mathrm{W} / \mathrm{m}^{2}\right)$ in the heat convection; $h_{f}$ is the convective heat transfer coefficient $\left(\mathrm{W} / \mathrm{m}^{2} \cdot \mathrm{K}\right) ; T_{s}$ is the temperature $(\mathrm{K})$ of the battery surface and $T_{b}$ is the temperature $(\mathrm{K})$ of the surround flow media.

We can calculate that the NCM battery selected can release its heat generated timely under normal temperature through analysis and calculation according to the heating mechanism of lithium-ion battery. However, if the external environment changes, it will change the battery performance as well as its heat production.

We can know that the temperature coefficient of electromotive force $(\partial E / \partial T)$ is related to the change of $\Delta S$ from Formula (4). At the same time, $\Delta \mathrm{S}$ and the battery SOC have a close relation. According to Literature [9], we can reach that the battery discharge reaction absorbs heat when $0.4<\mathrm{SOC}<1$ and $\Delta S>0$; the battery discharge reaction releases heat when $\mathrm{SOC}<0.4$ and $\Delta S<0$, and the temperature coefficient increases linearly along with the decrease of SOC. Formula (7) indicates that the battery heat production is directly related to the battery internal resistance and current multiplying power. Formula (8) and (9) indicates that the battery heat convection is closely related to environmental temperature. Therefore, experimental researches will be done on the battery under different environmental temperatures by cooperating with the above influence factors.

\section{Research on Lithium Ion Battery Thermal Characteristics}

In the test, the charging and discharging equipment Digatron MCT100-6-8, explosion-proof high-low temperature test chamber, temperature data collection and voltage acquisition device and others are adopted to conduct tests.

\subsection{Environmental and discharge capacity}

The testing method is as follows (taking $0.1 \mathrm{C}$ as an example): discharge the battery with $1 \mathrm{C}$ current to the non-conducting voltage under the indoor temperature, and place it for 1 hour; charge the battery with $1 \mathrm{C}$ current to $4.25 \mathrm{~V}$, charge it to $2.8 \mathrm{~A}$ current with constant voltage and place it for 1 hour; then place the battery in the high-low temperature test chamber for 2 hours in the set environmental temperature; finally discharge it with $0.1 \mathrm{C}$ current to unit voltage value $2.8 \mathrm{~V}$, and record the battery discharge capacity at this stage. $0.1 \mathrm{C}, 0.3 \mathrm{C}, 1 \mathrm{C}, 2 \mathrm{C}, 3 \mathrm{C}$ and $4 \mathrm{C}$ discharge rates will be selected in the test.

The experimental result is shown in Figure 1: the battery discharge capacity decreases along with the increase of the discharge rate and increases along with the increase of the environmental temperature. When the environmental temperature is lower than $25^{\circ} \mathrm{C}$, the reduce trend of the discharge capacity under high discharge rate is more obvious than that under lower discharge rate; when the environmental temperature is higher than $25^{\circ} \mathrm{C}$, the curve changes relatively stable.

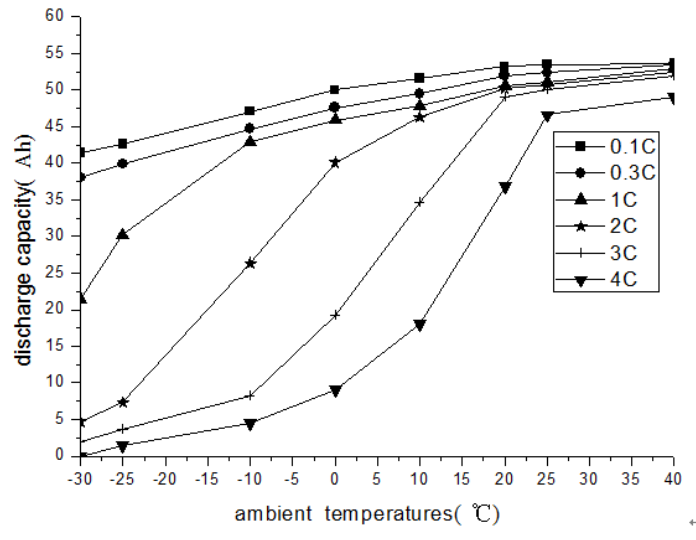

Fig. 1. Discharge capacity at different ambient temperatures

\subsection{Environmental temperature and DC internal resistance}

Refer to HPPC experiment for the method of testing the battery internal resistance. The testing method is as follows: empty the battery electric quantity firstly based on the testing method in 2.1 
section, then charge it fully and place it for 1 hour; discharge it with $1 / 3 \mathrm{C}$ constant current, discharge $10 \%$ rated capacity every time and place it for 1 hour; then conduct pulse charge and discharge on the battery to calculate the DC internal resistance. In the experiment, the SOC testing point selects $0.1,0.2,0.3,0.4,0.5,0.6,0.7,0.8$ and 0.9 under the environmental temperature of $-25^{\circ} \mathrm{C}, 0^{\circ} \mathrm{C}, 25^{\circ} \mathrm{C}$ and $40^{\circ} \mathrm{C}$ respectively.

The experiment indicates that the discharge internal resistance and charge internal resistance increase along with the decrease of temperature and increase along with the decrease of SOC; but the discharge internal resistance is larger than the charge internal resistance. As shown in Figure 2, when the environmental temperature is $25^{\circ} \mathrm{C}$ and $40^{\circ} \mathrm{C}$, the discharge internal resistance of the battery under different SOCs is with little difference; when the environmental temperature is $0{ }^{\circ} \mathrm{C}$ and $-25^{\circ} \mathrm{C}$, the battery internal resistance is relatively small within the SOC scope of $0.4 \sim 0.9$, and its change along with SOC is little. But when SOC is lower than 0.4, the discharge internal resistance has an obvious increase trend along with the decrease of temperature. As shown in Figure 3, during the charging process, when the environmental temperature is $0^{\circ} \mathrm{C}, 25^{\circ} \mathrm{C}$ and $40^{\circ} \mathrm{C}$, the internal resistance of the battery is with little difference under different SOCs, and it is relatively small; when the environmental temperature is $-25^{\circ} \mathrm{C}$, the battery internal resistance is very high, and the increase trend of the battery internal resistance is more obvious when SOC is lower than 0.4.

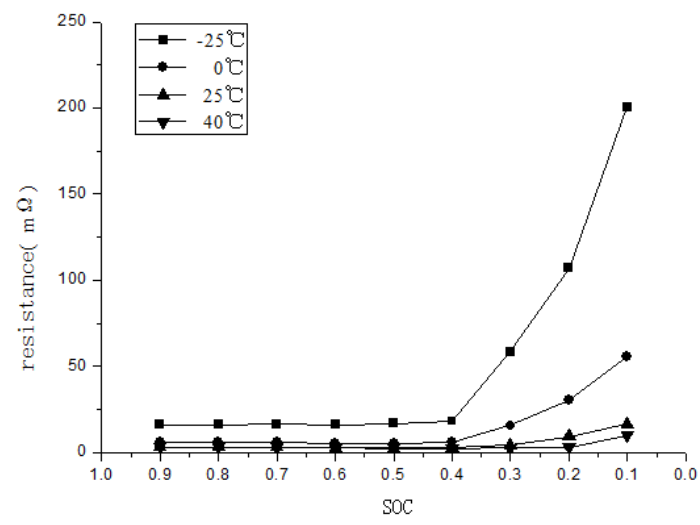

Fig. 2. The resistance of discharge and SOC at different ambient temperatures

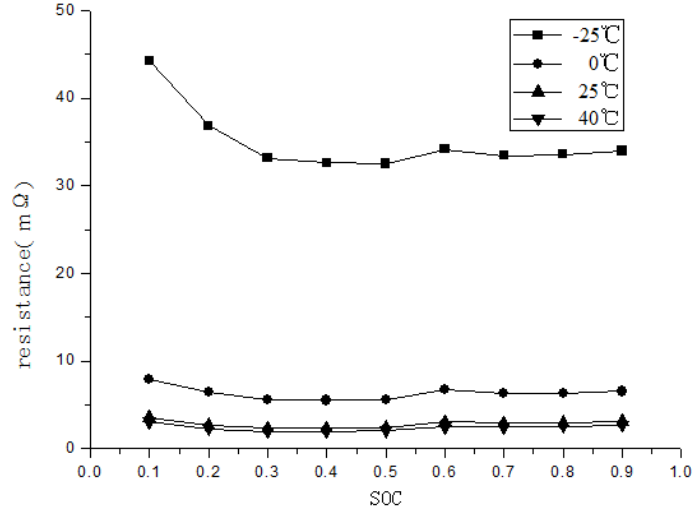

Fig. 3. The resistance of charge and SOC at different ambient temperatures

\subsection{Environmental temperature and open-circuit voltage}

The testing method is as follows: empty the battery electric quantity firstly based on the testing method in the 2.1 section, then charge it fully and place it;; set the high-low temperature test chamber at the demanded temperature, and place it for $2 \mathrm{~h}$; then discharge it with $1 / 3 \mathrm{C}$ constant current to the set SOC, and record the open-circuit voltage of the battery; respectively test 11 SOC points: $0,0.1$, $0.2,0.3,0.4,0.5,0.6,0.7,0.8,0.9,1$ and 4 environmental temperatures: $-25^{\circ} \mathrm{C}, 0{ }^{\circ} \mathrm{C}, 25^{\circ} \mathrm{C}$ and $40^{\circ} \mathrm{C}$ according to the above-mentioned testing method.

As shown in Figure 4, the open-circuit voltage of the battery reduces fast when the environmental temperature is the same and $\mathrm{SOC}<0.2$; the change of the open-circuit voltage of the battery along 
with the change of SOC is relatively stable when $\mathrm{SOC}>0.2$. Curves acquired under different environmental temperatures are different environmental temperature. The lower the environmental temperature during the charge and discharge process, the lower the open-circuit voltage.

When the environmental temperature is $0^{\circ} \mathrm{C}, 25^{\circ} \mathrm{C}$ and $40^{\circ} \mathrm{C}$, the relative difference of the battery open-circuit voltage is small; but the $-25^{\circ} \mathrm{C}$ curve is obviously lower. When SOC value is relatively lower, the battery open-circuit voltage is very small. With cooperating with contents in Section 1, we can know that the internal energy consumed by the lithium ion battery electrochemical reaction will increase obviously upon deep discharge, and it will bring about losses to the battery.

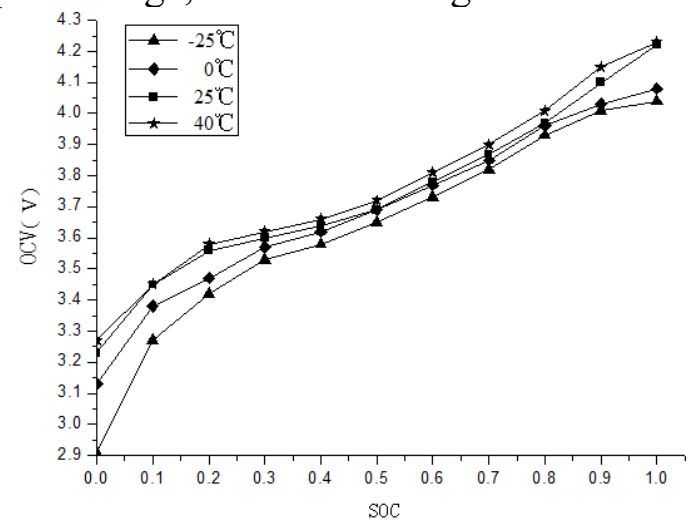

Fig. 4. SOC-OCV curves at different ambient temperatures

\subsection{Environmental temperature and discharge efficiency}

Discharge efficiency means the ratio between the actual capacity discharged under the regulated discharge system and the rated capacity. The actual discharge capacity of battery is required to reach $80 \%$ of the nominal capacity. Consider the batter life span based on the standard and find out the optimal work temperature scope. The experimental steps are the same as those in Section 2.1. Discharge the battery at $1 \mathrm{C}$ rate and test under different temperatures respectively.

From Figure 5, we can know that the unit discharge efficiency decreases obviously when the environmental temperature is higher than $40^{\circ} \mathrm{C}$ or lower than $0^{\circ} \mathrm{C}$. It is because the battery internal resistance increases obviously during low-temperature discharge; thus, the battery voltage reaches the discharge non-conducting voltage in advance, and the discharge capacity is decreased. Upon hightemperature discharge, internal materials of the battery are with irreversible attenuation, and the electrolyte concentration is too low at the same time, which reduces the discharge capacity. Moreover, we can know that the battery discharge efficiency is lower than $80 \%$ when the temperature is lower than $-15.5^{\circ} \mathrm{C}$ or higher than $53^{\circ} \mathrm{C}$ from the experimental data. Therefore, lithium ion batteries are not applicable to operate without auxiliary heat management when the environmental temperature is lower than $-15.5^{\circ} \mathrm{C}$ or higher than $53^{\circ} \mathrm{C}$. 


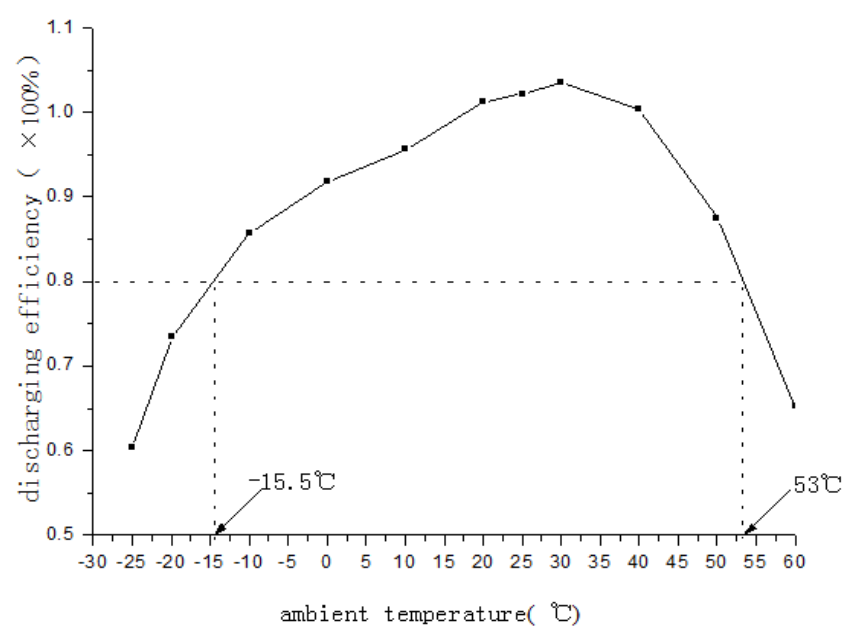

Fig. 5. Discharging efficiency of battery at different ambient temperatures

\section{Summary}

Important performances of NCM power battery under different environmental temperatures are analyzed by cooperating with the battery heating mechanism, and the following conclusions are acquired.

(1) The battery discharge capacity will decrease rapidly under low temperature, which increases fast along with the increase of temperature; but it is relatively stable under normal temperature. The increase of discharge capacity under high temperature will slow down.

(2) When the environmental temperature is indoor temperature and high temperature, the charge and discharge internal resistance is relatively smaller with little change upon different SOC values. Under low temperature, the charge and discharge internal resistance increases obviously along with the decrease of SOC. Therefore, the work environment of ternary lithium ion battery should be kept higher than $0^{\circ} \mathrm{C}$ based on the experimental data.

(3) The open-circuit voltage of the battery decreases along with the decrease of temperature, and the open-circuit voltage change caused by temperature difference increases along with the decrease of SOC values. Meanwhile, in consideration of the relation between entropy heat and SOC value, it is not suitable for NCM battery to discharge in depth under low temperature.

(4) According to the environmental temperature and discharge efficiency curve and cooperating with conclusions acquired, the battery temperature should be controlled between $0^{\circ} \mathrm{C} \sim 53^{\circ} \mathrm{C}$ in the heat management design of NCM batteries for vehicles.

Those conclusions define the temperature characteristics of ternary lithium ion batteries, which have significant meaning for the design of the battery heat management system.

\section{Acknowledgement}

This research was financially supported by the National Natural Science Foundation of China (Grant NO. 61473115)

\section{References}

[1] Z. Lei, C. Zhang, J. Li, Research on the Thermal Characteristics of EVs Lithium-ion Battery, Journal of Power Supply, vol.12, pp. 84-87, 2014.

[2] D. H. Doughty, P. C. Butler, R. G. Jungst, et al, Lithium battery thermal models, Journal of Power Sources, vol.110, pp. 357-362, 2002.

[3] A. A. Pesaran, Bttery Thermal models for hybrid vehicle simulations, Journal of Power Sources, vol. 110, pp. 377-382, 2002. 
[4] Q. Wang, J. Sun, X. Yao, et al, Thermal behavior inside lithium-ion batteries, Chinese Journal of Applied Chemistry, vol. 23, pp. 489-493, 2006.

[5] Z. Li, M. Tong, L. Lu, et al, Capacity characteristics of power lead-acid and LiFePO4 li-ion batteries, Battery Bimonthly, vol.39, pp. 26-28, 2009.

[6] Y. Ling, X. Fang, S. Wang, et al, Thermal management of lithium-ion batteries using phase change materials, Energy Storage Science and Technology, vol. 2, pp. 451-459, 2013.

[7] H. Li, Y. Jia, D. Zhang, et al, Heat production characteristics of power lithium-ion phosphate batteries, Chinese Journal of Power Sources, vol. 40, pp. 968-970, 2016.

[8] N. Xin, Thermal Characteristic Analysis and simulation research of lithium-ion power battery pack for pure electric vehicle, Jilin University, 2012.

[9] W. Zhai, X. Shi, Q. Zhu, et al, Test and analysis of OCV temperature coefficient of lithium-ion batteries, Chinese Journal of Power Sources, vol.11, pp. 1954-1955, 2013. 